Canadian University Music Review

Canadian University Music Review

Revue de musique des universités canadiennes

\title{
Metrical Reinterpretations in Ursula Mamlok's Panta Rhei, IV (1981)
}

\section{Roxane Prevost}

Volume 23, numéro 1-2, 2003

URI : https://id.erudit.org/iderudit/1014522ar

DOI : https://doi.org/10.7202/1014522ar

Aller au sommaire du numéro

\section{Éditeur(s)}

Canadian University Music Society / Société de musique des universités canadiennes

ISSN

0710-0353 (imprimé)

2291-2436 (numérique)

Découvrir la revue

Citer cet article

Prevost, R. (2003). Metrical Reinterpretations in Ursula Mamlok's Panta Rhei, IV (1981). Canadian University Music Review / Revue de musique des universités canadiennes, 23(1-2), 145-165. https://doi.org/10.7202/1014522ar
Résumé de l'article

La musique d'Ursula Mamlok (1928-) n'a pas attiré l'attention des chercheurs, même si la compositrice est devenue une figure marquante sur le triple plan de l'interprétation, de l'enregistrement et de l'édition. Le présent article s'attarde sur le quatrième mouvement de son trio bien connu, Panta Rhei (1981), en particulier sur la répétition d'un motif frappant de note répétée au début et pendant les refrains. Mamlok varie les entrées du motif, de sorte que surviennent des accélérations et décélérations, comme l'a décrit Hasty. En complétant tôt ou tard les projections, l'œuvre de Mamlok donne l'impression d'un « temps continu » ou Panta Rhei.
All Rights Reserved @ Canadian University Music Society / Société de musique des universités canadiennes, 2004
Ce document est protégé par la loi sur le droit d'auteur. L'utilisation des services d'Érudit (y compris la reproduction) est assujettie à sa politique d'utilisation que vous pouvez consulter en ligne.

https://apropos.erudit.org/fr/usagers/politique-dutilisation/ 
METRICAL REINTERPRETATIONS IN

URSULA MAMLOK'S PANTA RHEI, IV (1981) ${ }^{1}$

\author{
Roxane Prevost
}

Composer Ursula Mamlok (b. 1928) has gained prominence in the areas of performance, recording, and publishing in the past four decades. She is cited in most books on influential women composers of the twentieth century and has entries in both Baker's Biographical Dictionary of Musicians (Slonimsky and Kuhn 2001) and the New Grove Dictionary of Music and Musicians (Sadie 2001). At least fifteen different recordings, released on labels including CRI Recordings, Opus One, Leonarda, and Grenadilla, and forty-five scores, published by C. F. Peters, American Composers Alliance, McGinnis and Marx, and Casia, are available. Most recently, a recording devoted to her works (Mamlok 1999), as well as a recording with digitally remastered previously recorded works (Mamlok 2002), were released. The majority of these recorded works draw from serial techniques.

One of Mamlok's most popular serial works, Panta Rhei (1981), has received numerous performances throughout North America; in addition, this trio-for violin, cello, and piano-has been recorded by three different groups. ${ }^{2}$ Surprisingly, this remarkable piece has received little or no scholarly attention. A metrical analysis of this piece reveals the need to develop a metrical theory that is better suited to deal with music, such as Panta Rhei. Mamlok, who translates the Greek title of this work as "time in flux" or "everything is in flux" (Mamlok 1984b, 2000, liner notes), adopts the concept of "everything is in flux" for Panta Rhei from Heraclitus's "philosophical concept of perpetual becoming and passing of all things" (Mamlok 1984b, liner notes). The key to understanding Mamlok's piece is to understand how she portrays as rhythmic structures the concept of "time in flux." I argue that her technique involves establishing a pattern of pulses or beats for the listener by repeating similar metrical patterns, but then subtly altering the listener's anticipation of where the beat should occur by moving unexpectedly its position in temporal space. ${ }^{3}$ The end result is that the listener perceives time as either accelerating or decelerating, that is, perceives time as "time in flux." Christopher Hasty's analytical model, which proposes that meter can be inter-

1 I would like to thank the anonymous readers for their criticism and insightful comments.

2Three recordings have been released on Mamlok 1984a, 1984b, 2000.

3 I define beat as a point in time, which has been predetermined by an established periodicity from preceding events, but which can also be altered with new events. 
preted as a process rather than strict periodicity, is adapted to describe the elasticity of the metrical structure in Panta Rhei.

Panta Rhei's fourth movement, "Allegro energico," opens with a four-note unit that marks each of the A sections of its rondo form. ${ }^{4}$ This four-note unit is distinctive because one instrument repeats the same pitch in short durations, making it recognizable to listeners. In addition to its rhythmic profile, the motive is marked by accents on the first note, loud dynamics (fortissimo) that soften to piano on the last note, and open strings that are doubled at the unison in the violin and cello (appendix). Mamlok articulates this repeated-note unit both with duple and triple subdivisions in the returning A sections, thus giving the listener a sense that the unit has either a duple or triple rhythmic interpretation (as will be seen in examples $1 b$ and $3 b$ ). But, because the unit is contextually distinctive, the listener most likely associates the return of the unit with the beginning of an A section. Although my analysis shows that a strict duple meter is severely skewed, Mamlok nonetheless makes us perceive a metrical structure; thus rather than being chaotic, the metrical structure is fluid and flexible. Interestingly, durations are serially derived in some of the A sections, but I focus on the flexible metrical structure, which is more tangible for the listener. ${ }^{5}$ Before exploring the metrical structure in the five A sections of Panta Rhei, I discuss briefly some of the key concepts that I borrow from Hasty's theories that will be useful in my analysis of Mamlok's work. Hasty's theories offer useful analytical tools for the analysis of this work because the projected meters in Mamlok's music do not always coincide with notated measures.

In Meter as Rhythm, Hasty argues that meter is an aspect of rhythm and not an element that should be separated from rhythm. ${ }^{6}$ Hasty describes a durational projection as an event that has a potential projection than can be realized when a second event enters where the potential projection was expected to end. Thus, each event activates a potential projection that may or may not be realized. In order for the projection of a meter to be realized, at least one continuation (or anacrusis) must occur. Hasty describes duple meter as equal and consisting of at least three projections. One event begins the potential projection, as illustrated with the dotted line of $P$ (the potential projection of the quarter note) in figure $1 \mathrm{a}$, while the second event, the continuation, completes it, as illustrated by the full line in figure $1 \mathrm{~b}$. But, the second event also begins a potential projection, which is realized itself by the beginning of the next event. In a duple

4Mamlok derives the pc material of the episodes through the rotation of twelve-tone rows. For more on serial techniques in Panta Rhei, see Prevost (2003, 132-49).

5 The durations of the vertical sonorities that accompany the repeated-note motive unfold a series (with the sixteenth-note basic unit) of 11 durations in section Al (example 1a) $<7-4-11-8-3-10-9$ 6-2-5-1-(12) $>$ and 10 durations in section $A 2$ (example $1 \mathrm{~b}$ ) $<1-5-2-6-9-10-3-8-7-4-(11)-(12)>$. (Part of this row $<1-5-2-6-9-10-3-8>$ is the retrograde of part of the first row.) The durations of the chords in sections $A 3<7-5-6-9-3-8-13-2-6-1>$ and $A 4<8-3-12-7-4-11-5-2-11-1-9>$ unfold only partial durational series. The entries of the repeated-note motive and the vertical sonorities do not appear to relate through serial procedures.

6Gretchen G. Horlacher (2001), adopts Hasty's theories (1997, 1-26) to offer a metrical interpretation of Bartók's music. 
meter, we can perceive a return to the initial event after the completion of the projection. Thus, in a duple meter three durational projections occur: (1) the first event to the second event; (2) the second event to the third event; and lastly (3) the first event to the third event (Hasty 1997, 130-32). In figure $1 \mathrm{~b}, \mathrm{Q}$ represents the potential projection of the half note, which if realized would negate the potential projection of the dotted-half note $P$ (labeled with an " $x$ "). A durational projection can thus be metrical because if realized, the listener can perceive a duple meter as in the case of figure 1 .

a)

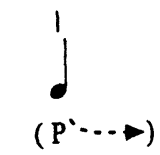

b)

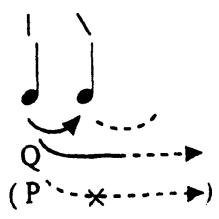

Figure 1. Hasty, Meter as Rhythm: Projections for equal measures (Hasty 1997, 132*)

* Only part of Hasty's Figure 9.18 is reproduced here.

Although I analyze the five A sections in the fourth movement of Panta Rhei in a $2 / 4$ meter, the internal division of the repeated-note unit can be interpreted as both equal and unequal (divided into three), depending on its articulation (examples $1 \mathrm{~b}$ and $3 \mathrm{~b}$ ). In fact, Mamlok plays with metrical projections in Panta $R$ hei by realizing projections, but not always where the listener anticipates the realization of these projections to occur. The aural effect is one of what Hasty describes as decelerations, notated as "rit.," and accelerations, notated as "accel." Perceived accelerations and decelerations occur when the realization of the potential projection occurs too early or too late. The realization or ending of the event occurs in close proximity of the potential projection's ending so that the listener can adjust to perceive the second event as the realization of the projection and not solely as a new projection. This perception of pulling and pushing of time for the listener and for Mamlok mimics or translates to the "flux" of time.

\section{SECTION A1}

All five A sections of Panta Rhei accommodate a duple meter and are marked by the return of a repeated-note unit. In section A1, perceived accelerations and decelerations occur with the return of the repeated-note unit, which at times arrives too early or too late. Example la shows the rhythmic scheme of section A1. I join 
the violin line (upward stems) with the cello line (downward stems) on the upper staff and include the piano part on the lower staff. Because the four-note unit has a strong rhythmic profile-that is, the repeated pitch in one instrument-changing its entries within the measure skews the listener's perception of the beat. The perceived decelerations and accelerations do not result from a displacement of the tactus or subtactus, but from the displacement of the unit, the beginning of which is associated with a strong beat. In order for an event to be perceived as early, it must occur within an eighth note or less of the potential projection because the tactus is the quarter-note duration. A longer duration will disrupt the process of the projection which then will not be realized. An event will be perceived as arriving late if it occurs an eighth note or a shorter duration after the potential projection.

I borrow Hasty's symbols to illustrate the potential projection, notated with dotted lines, and the realizations of projections, notated with full lines in example 1a. The vertical lines at the top of the example show the perceived downbeats, while the diagonal lines illustrate the continuations necessary to establish duple meter. In the first measure, a projection of the quarter note is realized with the piano chords. A potential ending is projected for the following quarter-note duration, but the repeated-note motive enters one sixteenth note early in the cello. The realization of the projection is thus early and a perceived acceleration occurs, as illustrated in example $1 \mathrm{~b}$, which shows the rhythmic effect of the different placements of the unit within the renotated measure. Because the cello unit moves the beginning of the projection by one sixteenth note, the violin's repeated D4s in bar 2 enter in phase with the cello's entry. When the cello states the unit in bar 3 , however, it once more enters one sixteenth note early, again resulting in an acceleration. The violin's entry in bar 4 accommodates the new beginning of the projections. When the cello returns with the $\mathrm{D} 3 \mathrm{~s}$ in bar 5 , it overlaps with the violin statement. The effect is, once more, a metrical acceleration that results from the omission of one sixteenth-note duration. The asterisk in example $1 \mathrm{~b}$ indicates that the renotated measure is incomplete. In bar 6 , the violin returns with the D4 repeated unit. This time, an acceleration occurs because the unit enters one eighth note early. When the cello returns in bar 7 , the realization of the potential projection is again shifted by one sixteenth note because the projection ends one sixteenth note too late, thus resulting in what one perceives as a deceleration. In bar 8, one now perceives an acceleration when the violin returns with the repeated D4s one eighth note early, with the cello doubling at the octave the last two D4s of the violin. The cello does continue to state the full unit, thus creating the effect of an acceleration because it enters one eighth note early. An acceleration occurs when the violin returns with the repeated D4 unit because it interrupts the eighth note of bar 9 by one sixteenth note. 


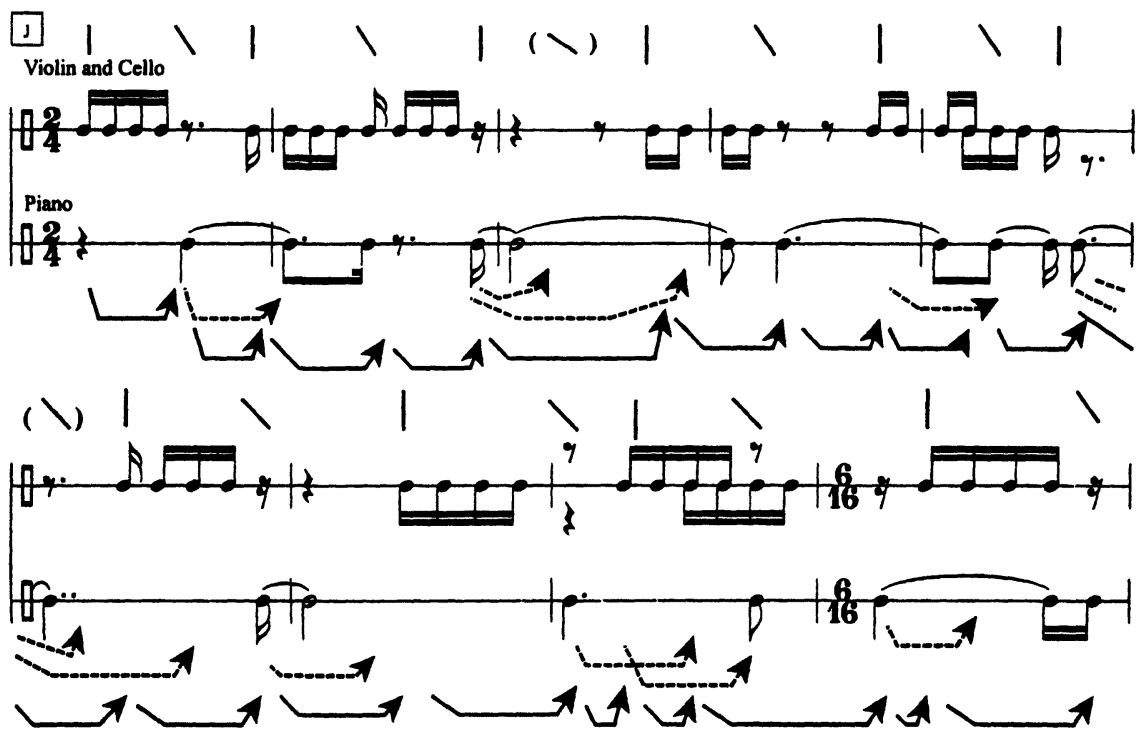

Example 1a. Panta Rhei, IV: Rhythmic profile of section Al (bars 1-9)
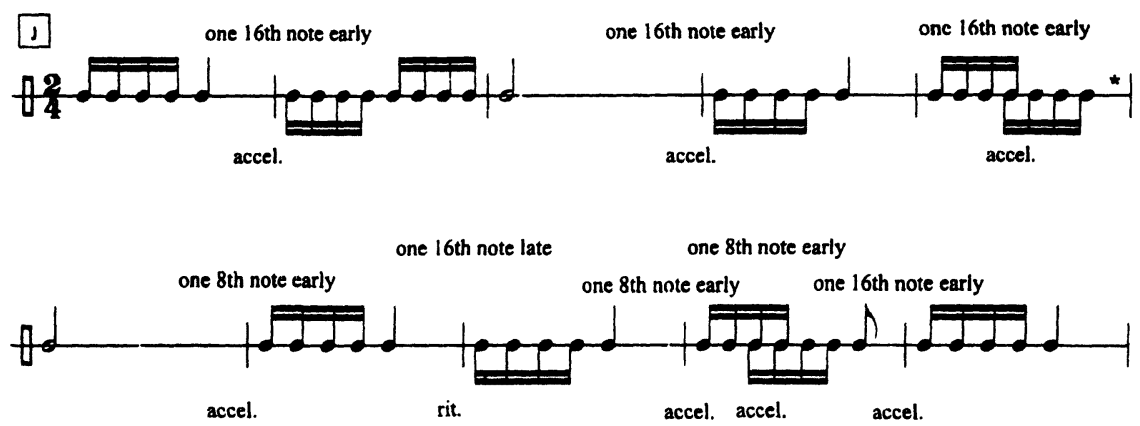

Example 1b. Panta Rhei, IV: Metrical analysis of section A1

\section{SECTION A2}

The return of the repeated-note unit marks the beginning of section $\mathrm{A} 2$ at letter $\mathrm{M}$. This time the unit occurs in the piano part and at different pitch levels, but as in example 1, the metrical structure is flexible because of the early or late return of the repeated-note unit (or the ending of the projections). Example 2a shows the durations of the three instruments without Hasty's symbols, but the processes are the same. When a projection is realized too early or too late, perceived accelerations and decelerations occur, as notated in example $2 \mathrm{~b}$. With the return of the repeated notes, which is accented, comes the beginning of a projection 
because like in section A1, the unit marks the beginning of an event. ${ }^{7}$ I adjust the measures in example $2 b$ to accommodate the first entry of the unit. In bar 21 , a deceleration occurs because the second statement of the unit begins one sixteenth note late. When the unit returns in bar 22, it overlaps with the second statement of the unit. Since the two unit statements overlap, the entry of the unit at the beginning of bar 22 occurs early, as illustrated in example $2 b$. The renotated score accommodates the overlapping statements with an incomplete measure. An acceleration also occurs with the overlapping statements because the realization of the projection with the second statement of the unit occurs one eighth note early.

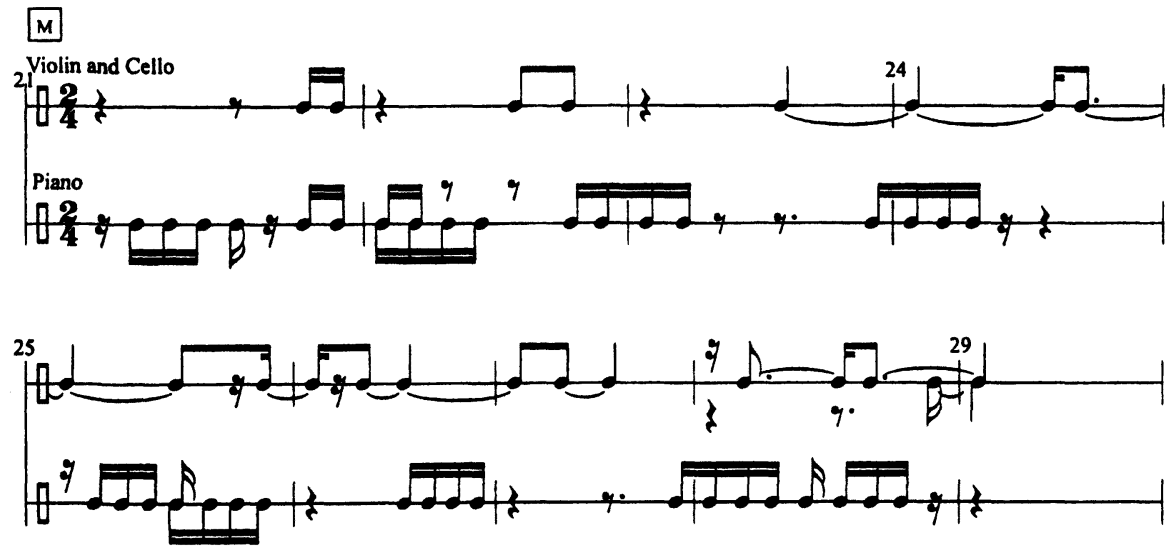

Example 2a. Panta Rhei, IV: Rhythmic profile of section A2 (bars 21-29)

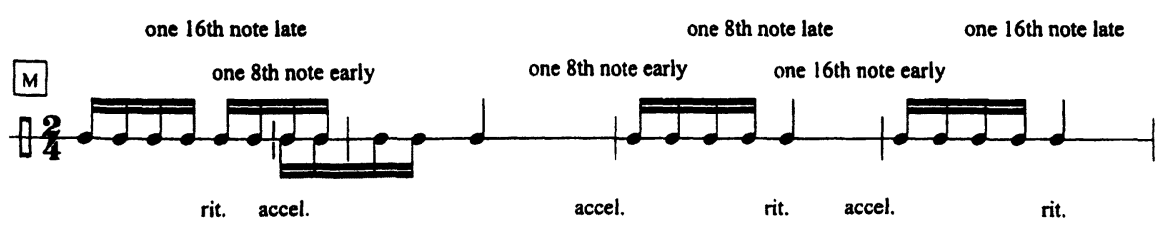

one 16 th note early

one 16 th note late

one 16 th note early one 8 th note late

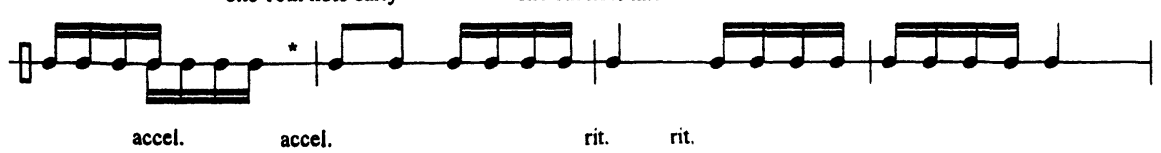

Example 2b. Panta Rhei, IV: Metrical analysis of section A2

7Although an accented D2 occurs in the piano at the beginning of section A2, the repeated-note unit marks the beginning of the $A$ return because it is accented, repeated, and in a higher register. 
A second acceleration occurs before the next entry of the unit because the quarter-note duration in example $2 b$ replaces the eighth-note duration of the score. Thus, one eighth-note duration is missing in order to realize the potential projection. The fourth entry of the unit is followed by an eighth-note rest. Since we expect a quarter note to follow the unit, a deceleration occurs. But, this deceleration is offset by the acceleration that occurs with the early entry of the unit at the end of bar 23; the unit enters one sixteenth note early. Once more the quarter note that is expected to follow the unit enters late. A deceleration occurs because the quarter note enters one sixteenth note late. The next entry of the unit begins in bar 25 . Although this entry occurs on the beat, the next entry overlaps with the last sixteenth note of the first unit in bar 25 . This does not only result in an acceleration, but also shifts the potential projections by one sixteenth note; thus, the renotated measure is incomplete. The next entry of the unit in bar 26 occurs on the beat. A deceleration occurs with the following quarter note, which enters one eighth note late. A deceleration also occurs before the next entry of the unit at the end of bar 27 because the unit enters one sixteenth note late. The last entry of the unit in section A2 occurs in bar 28 on the beat.

\section{SECTION A3}

Like sections $\mathrm{A} 1$ and $\mathrm{A} 2$ displacements in the recurrence of the repeatednote motive produce projections that are realized early or late, but section $\mathrm{A} 3$ differs from $\mathrm{A} 1$ and $\mathrm{A} 2$ in that the repeated-note unit now assumes a triple identity. Section A3 begins with the return of the repeated-note unit in bar 52. The unit consists of four repeated notes, but the other instruments do not respond immediately with an accented vertical sonority as in sections $A 1$ and A2, as shown in example 3a. The result is that of three short durations followed by one long, reminiscent of the fate motive from the first movement of Beethoven's Fifth Symphony. The last event, the fourth sixteenth note, receives an agogic accent because the vertical sonority that should follow does not occur. The eighth-note triplets that pulsated through the preceding section, B2, reemphasize the triple subdivision. Therefore, the repeated notes of the unit now assume a triple instead of a duple identity. The reinterpretation of the sixteenth notes as eighth-note triplets also affects the reinterpretation of other durations, as summarized in figure 2. I reinterpret the dotted-quarter note of the score as a half note in example $3 b$, the dotted-eighth note as a quarter note, and the dotted-sixteenth note as an eighth note. I reinterpret the durations to simplify the analysis and make it more accessible to the reader.

In bar 52 (example 3a), a deceleration occurs when the unit enters one sixteenth note late. The quarter note that follows in example $3 a$ occurs on the beat, but the sixteenth notes enter on the offbeat. The eighth note triplet of example $3 b$, then, is one sixteenth note late, thus creating a perceived deceleration. The unit returns in bar 54 in the violin part. An acceleration occurs because the violin enters one sixteenth note early. The longer durations of the 
P
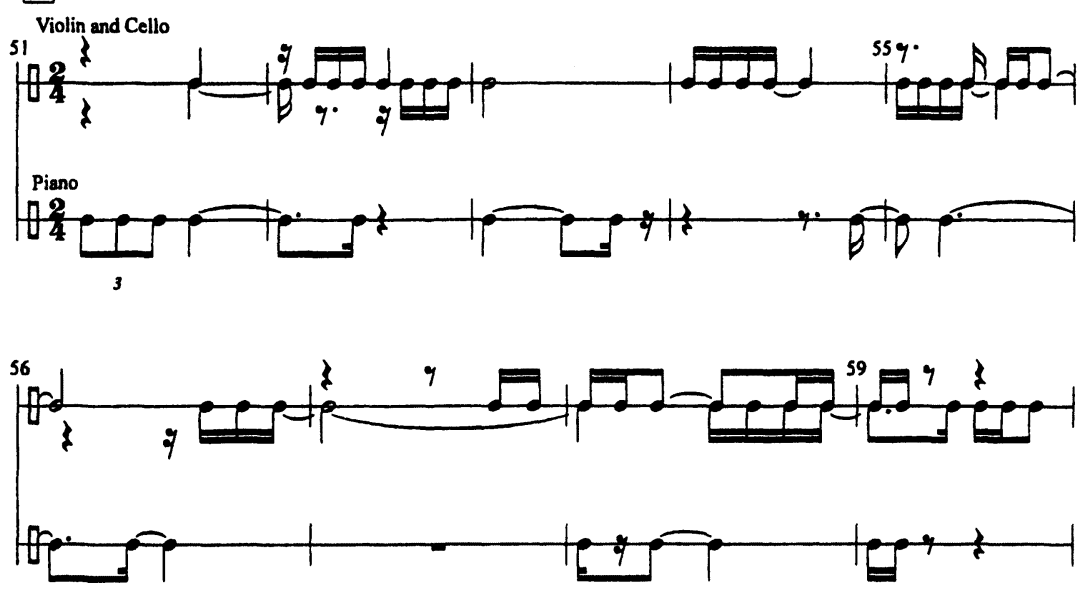

Example 3a. Panta Rhei, IV: Rhythmic profile of section A3 (bars 51-59)

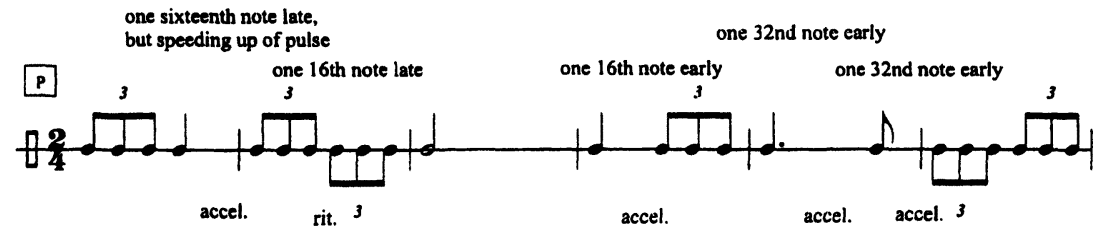

one 16th note early

one 16 th note late

one 16th note early in upper triplet

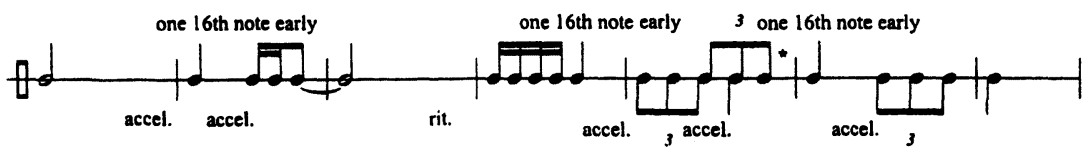

Example 3b. Panta Rhei, IV: Metrical analysis of section A3

\begin{tabular}{|l|l|}
\hline in score & reinterpretation \\
\hline$d$. & $d$ \\
\hline$\delta$ & $d$ \\
\hline$d$ & $d$ \\
\hline
\end{tabular}

Figure 2. Reinterpretations of durations in section A3 
dotted quarter note and the eighth note in bar 55 do not conform with the potential projection. Both of these durations lack one thirty-second duration in order to be complete. Thus, an acceleration occurs twice in the reinterpreted measures. The sixteenth-note unit returns on the downbeat of the cello line in bar 55. The violin responds with the unit on the next downbeat and is then followed by a half-note duration in the piano. Since the realization of the potential projection falls short one sixteenth note, an acceleration occurs to the next downbeat. In bar 56, the cello states the beginning of the repeated-note unit, but the result is that of two eighth notes and a quarter note, which is sustained into the next measure. Since the half note of example $3 b$ is one sixteenth note too long, the listener perceives a deceleration. The next entry of the unit occurs in bar 57, but the unit consists of five attacks, momentarily shifting back to its duple identity. An acceleration occurs with the next entry of the unit since the cello enters one sixteenth note too early. In bar 58, the overlapping unit, now with three attacks, results in an incomplete measure in the renotated score because one of the triplet statements occurs one sixteenth note early. The last entry of the unit in section A3 clearly states the triple identity of the unit with four attacks, but the triplets enter one sixteenth note early. Thus, unlike in sections $A 1$ and $A 2$, the unit projects both duple and triple meters in section A3.

\section{SECTION A4}

Like sections $A 1$ and $A 2$, section $A 4$ begins with the duple repeated-note unit, as shown in example 4a. But this section is the most metrically ambiguous of all of the A sections because the internal divisions of the quarter-note projection shift from duple to triple and many of the projections are once more realized too early or too late. The unit first enters on the second beat of bar 71; it returns in bar 72, but this time it is truncated to only three attacks. This gives the effect of two short durations versus one long, as illustrated in example $4 \mathrm{~b}$. A perceived acceleration occurs because the potential projection is realized by the piano, which enters one sixteenth note early in bar 72. The next entry of the unit occurs at the end of bar 72 and at the beginning of bar 73. An acceleration occurs because the cello enters one sixteenth note early. Since the unit consists of four attacks and is not followed by an attack in the piano part, the unit returns to its triple identity. A deceleration occurs when the reinterpreted quarter note of the piano enters one sixteenth note late. When the unit returns in bar 74 in the violin, it again enters one sixteenth note late, resulting in a perceived deceleration. The same occurs with the cello entry in the next measure. The last pitch of the repeated notes in the cello entry should coincide with the violin entry in bars 75 and 76. Since the unit enters one sixteenth note late in the violin, the listener perceives a deceleration. The entry of the half note also occurs one sixteenth note late and thus results in a perceived deceleration. In bar 77, the cello states the unit, as shown in example 4a. Since the projection is realized by the unit, which enters one eighth note early, an acceleration can be perceived. When the unit returns in the violin at the end of bar 77 and the beginning of bar 78, it conforms with the established beat in both examples $4 \mathrm{a}$ and $4 \mathrm{~b}$. The listener 
perceives an acceleration with the next entry of the unit because the cello enters with the unit one sixteenth note early. The last entry of the unit in section A4 overlaps the cello statement by one sixteenth note in the violin line; the penultimate measure in example $4 \mathrm{~b}$ is thus renotated as incomplete. Unlike in section $\mathrm{A} 3$ where the projected meter began as triple, changed to duple, and returned to triple, the projected meter in section A4 begins with duple and changes to triple for most of this section.
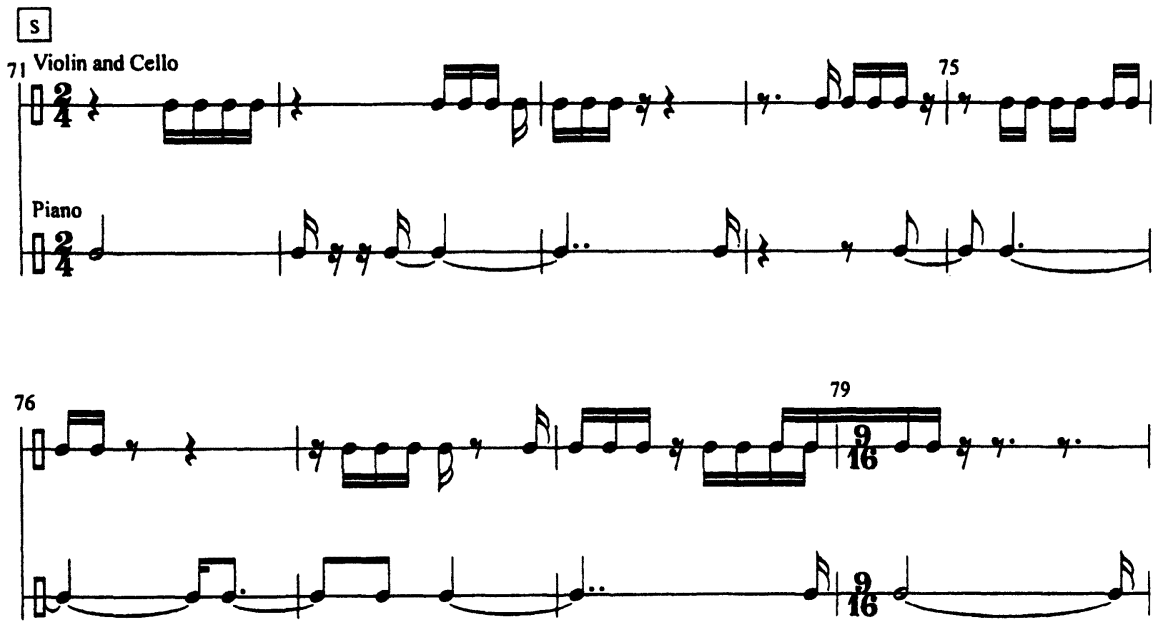

Example 4a. Panta Rhei, IV: Rhythmic profile of section A4 (bars 71-79)

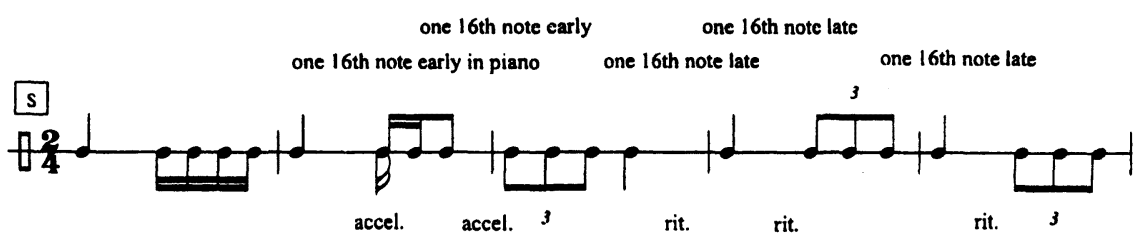

one 16 th note late

one 16th note early (lower triplets)

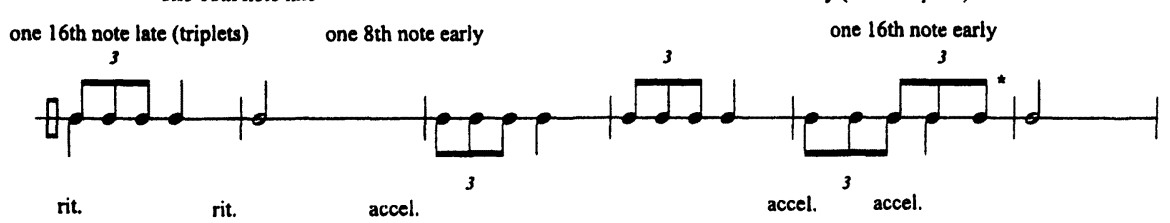

Example 4b. Panta Rhei, IV: Metrical analysis of section A4

\section{SECTION A5}

The last section of the fourth movement, section A5, consists solely of the repeated-note unit, but once more the metrical structure is flexible because of the potential projections and their early realizations. In bar 90 , the unit begins with three attacks on D4 in the piano part, but the string instruments do not 
respond, as shown in example 5a. Thus the unit retains a duple identity, as shown in the first measure of example $5 \mathrm{~b}$. When the piano states the same figure twice in a row, an acceleration occurs because the projection of the quarter note is realized one sixteenth note early. The piano states this unit once more in bar 92 , and is now doubled at the unison by the violin. The listener perceives an acceleration because the unit enters one sixteenth note early. The next entry of the unit occurs in the piano and violin in bar 94. Once more, the unit enters one sixteenth note early, resulting in a perceived acceleration. The last two statements of the unit occur in the last measure of example 5a with all of the instruments doubled at the unison D4. Since the combined statements result in six consecutive sixteenth notes, the effect, as shown in example $5 \mathrm{~b}$, is that of an acceleration, whereby the second statement of the unit enters one sixteenth note early.

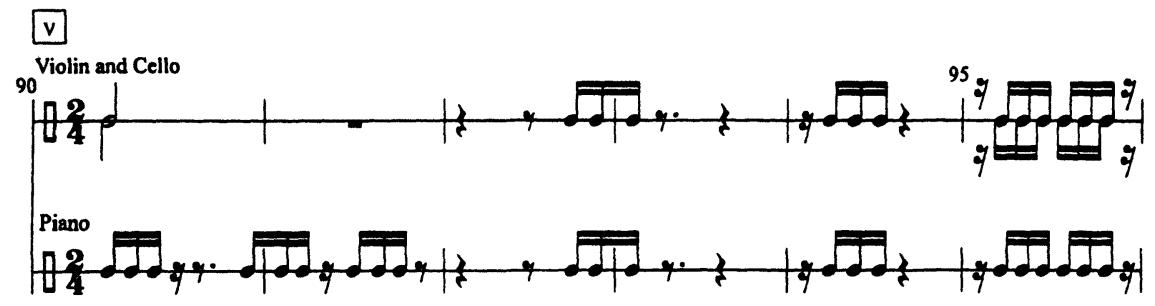

Example 5a. Panta Rhei, IV: Rhythmic profile of section A5 (bars 90-95)

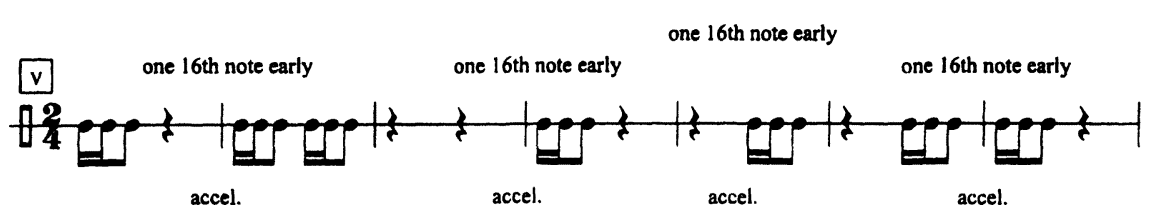

Example 5b. Panta Rhei, IV: Metrical analysis of section A5

My reinterpretation of Mamlok's original score shows that the repeated-note unit at the beginning of the A sections can be interpreted metrically as either duple or triple, depending on the number of consecutive repetitions of the same pitch, dynamics, and the placement of attacks. In section A1, the unit is clearly duple because five attacks occur: four for the repeated unit and one for the accented piano vertical sonorities. In section A2, the piano states the repeated unit, while the strings respond with vertical sonorities. Thus, the unit remains duple with five attacks. In section $\mathrm{A} 3$, the unit becomes triple, even though it still consists of four attacks, because the piano does not respond with accented vertical sonorities. Section A4 begins with the unit as duple, but by the third measure, the unit has slipped back to its triple metrical identity. Lastly, in 
section A5, only the unit is stated. It returns to a duple identity, but now truncated to half of its original length.

Although the different metrical identities of the unit, the overlapping statements of the unit, and the reinterpreted incomplete measures all contribute to the elasticity of the metrical structure in this movement of Panta Rhei, it is the many instances of perceived accelerations and decelerations that give the piece the impression of "time in flux." Mamlok sets up the listener with potential projections, but then alters many of their endings. In many instances the composer completes some of the projections early or late, thereby forcing the listener to reinterpret the beginning of new projections throughout the $\mathrm{A}$ sections of Panta Rhei. Mamlok provides the listener with the effect of accelerations and decelerations by pulling and pushing the ends of the projections, thereby giving the impression of "time in flux." 
Appendix. Ursula Mamlok, Panta Rhei, IV. (O 1982 by C. F. Peters Corporation. All rights reserved. Used by permission.

(5)
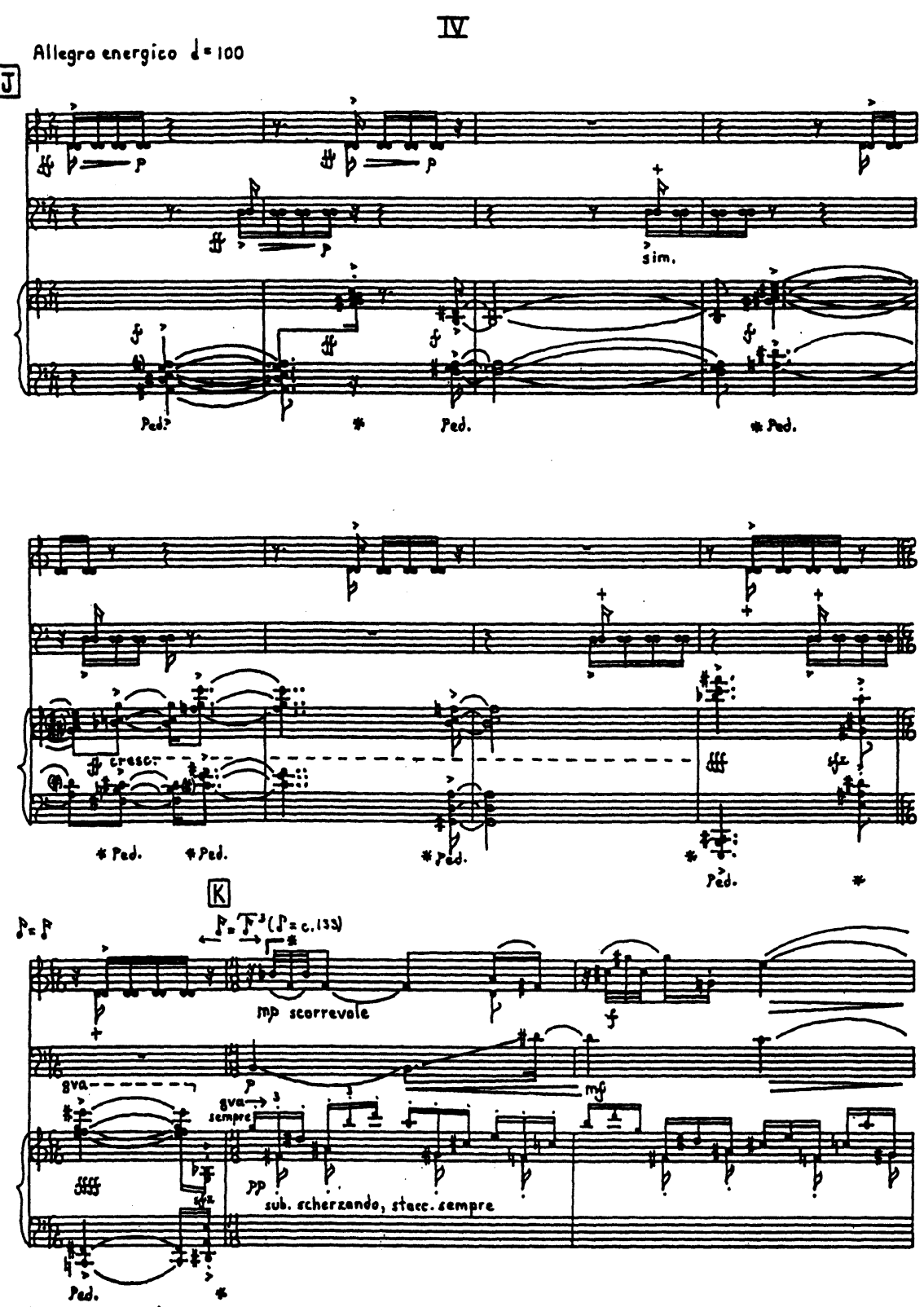

- 7-Arincipal voice 

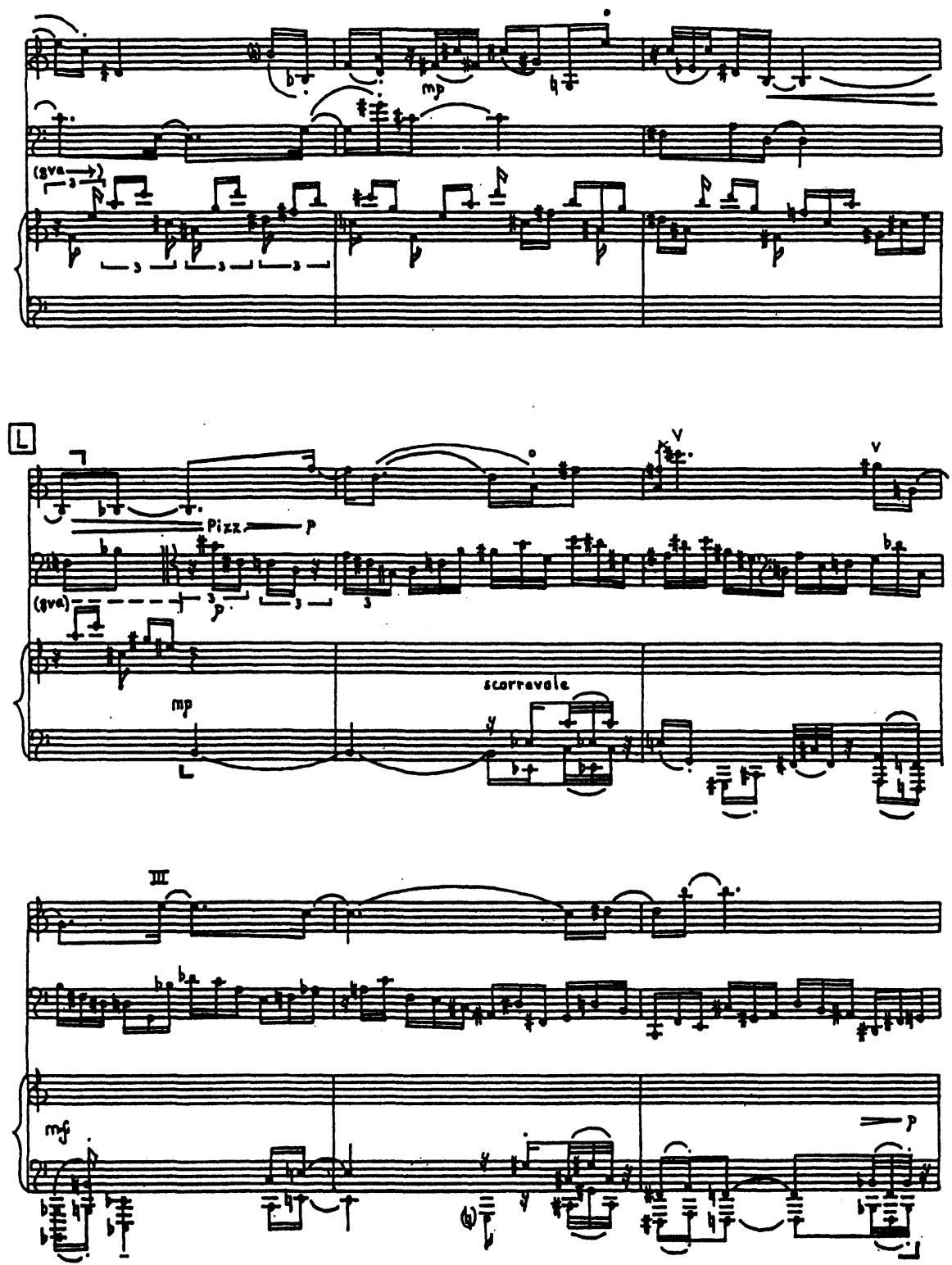
M
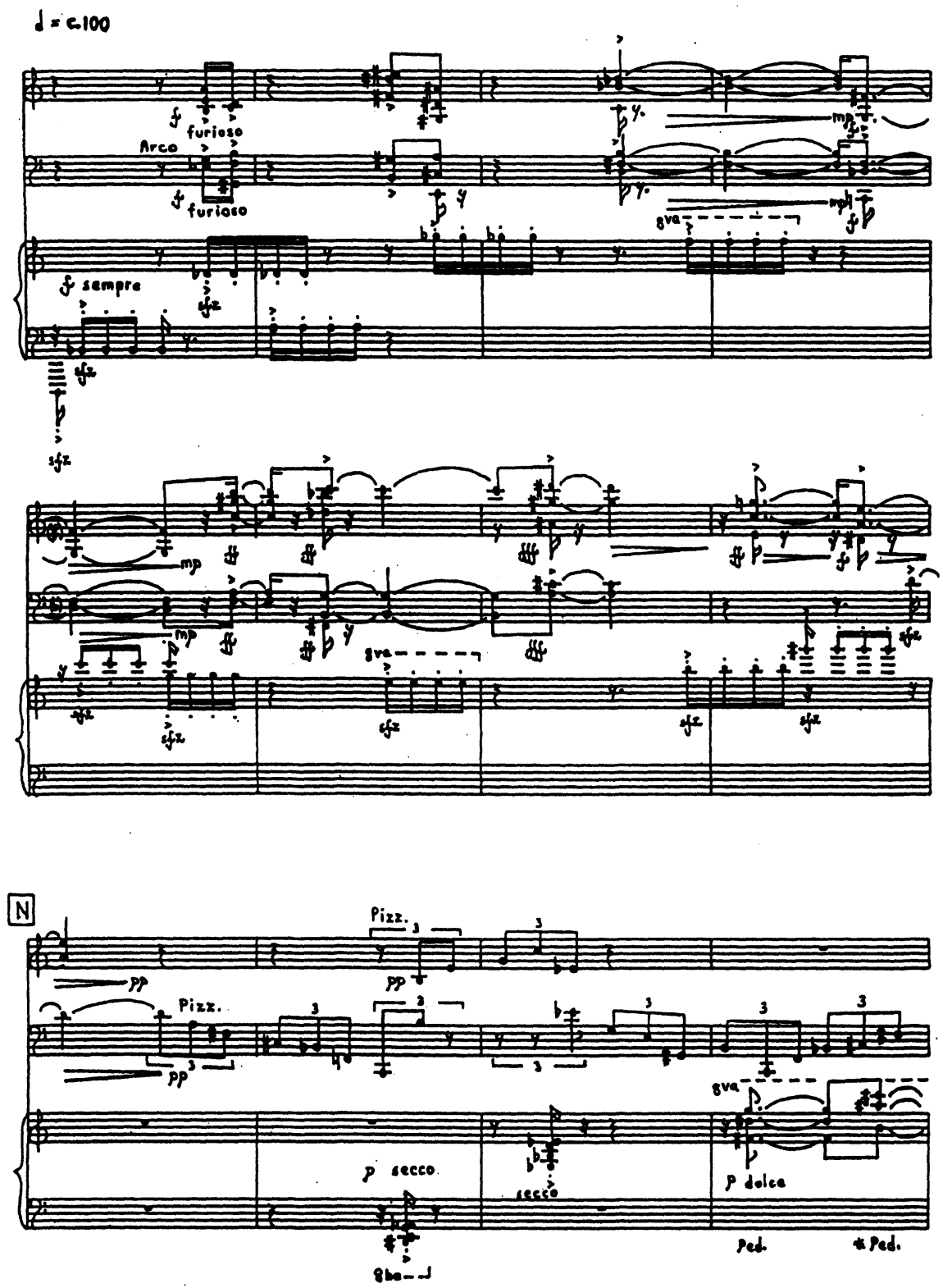

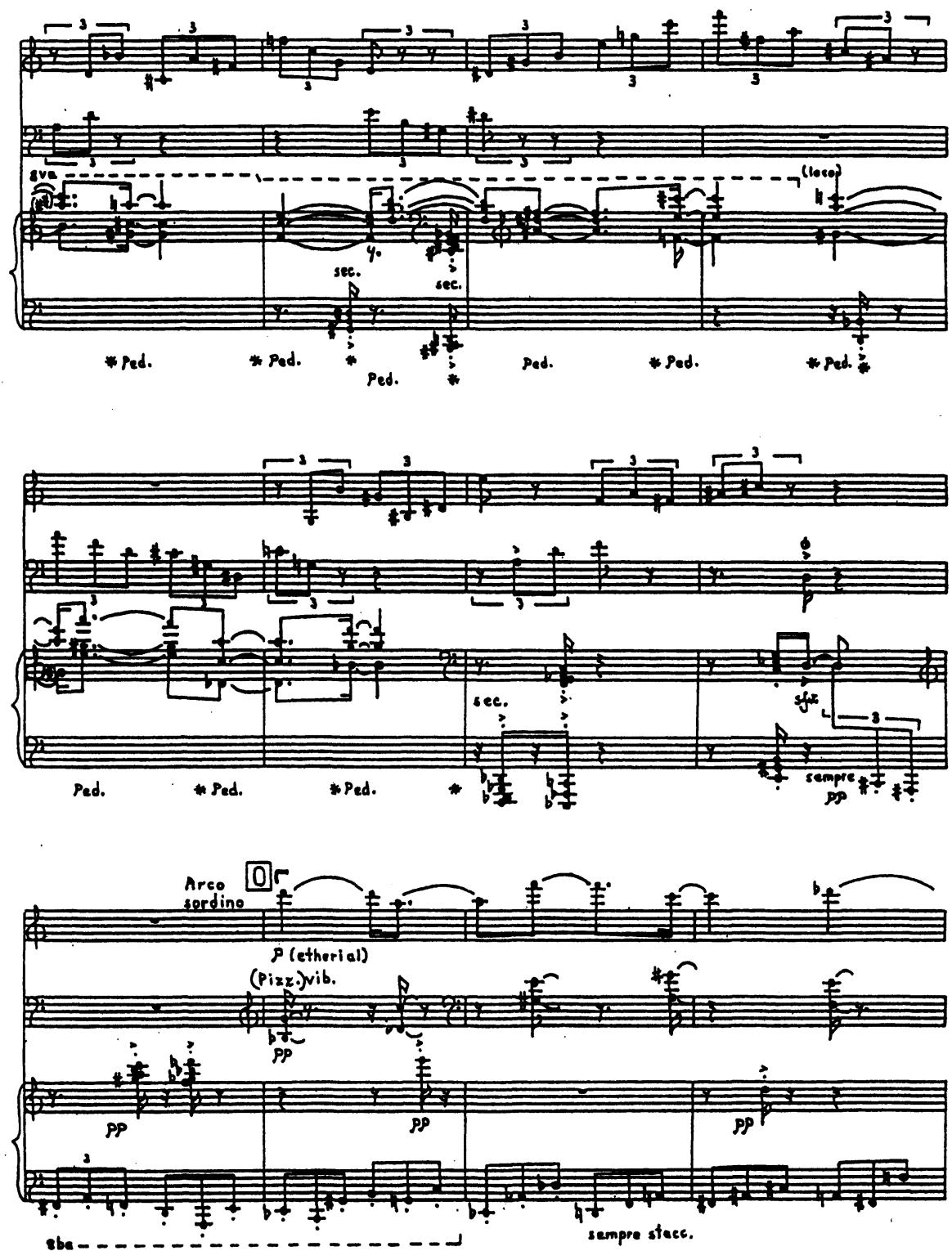

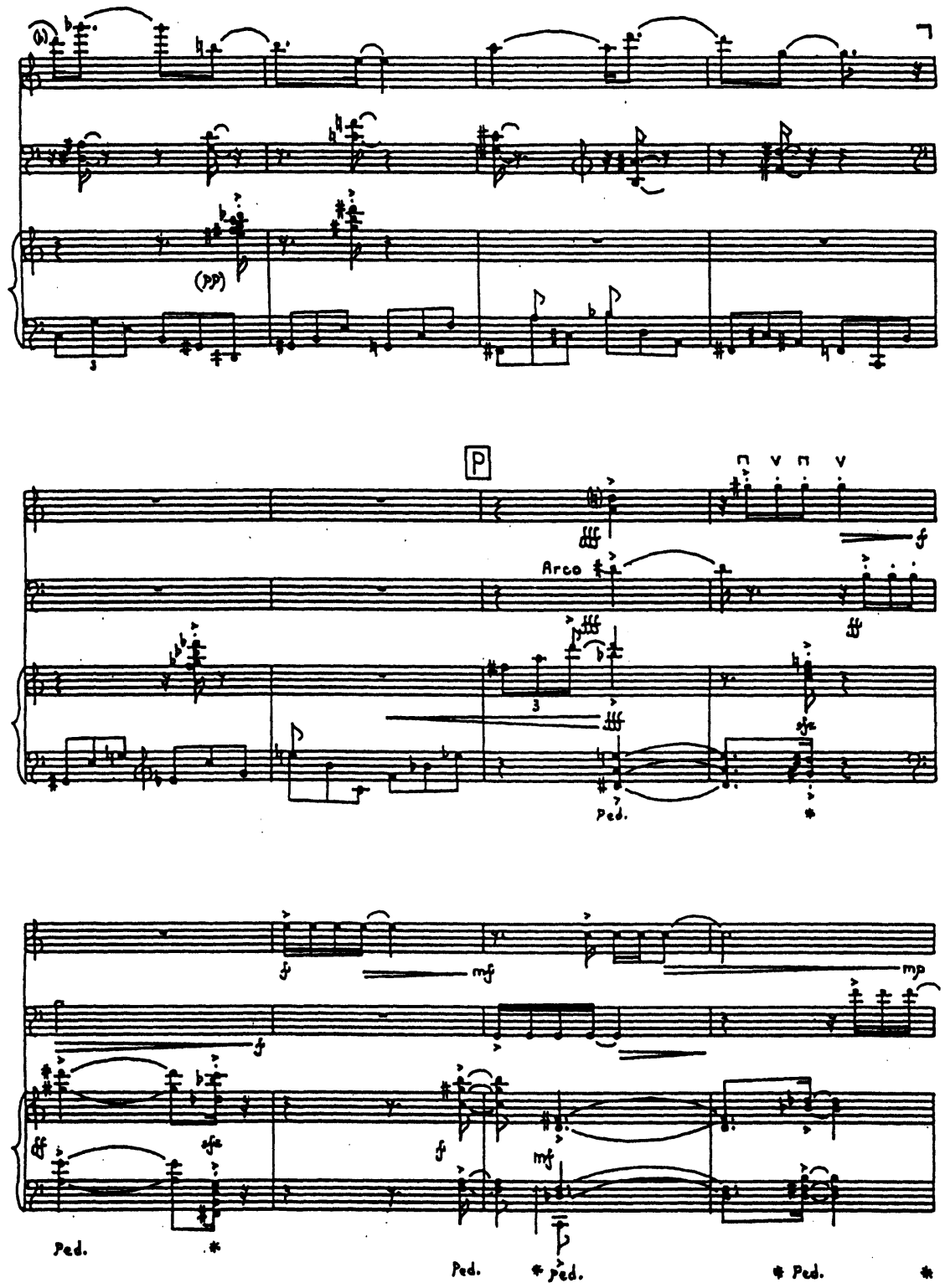

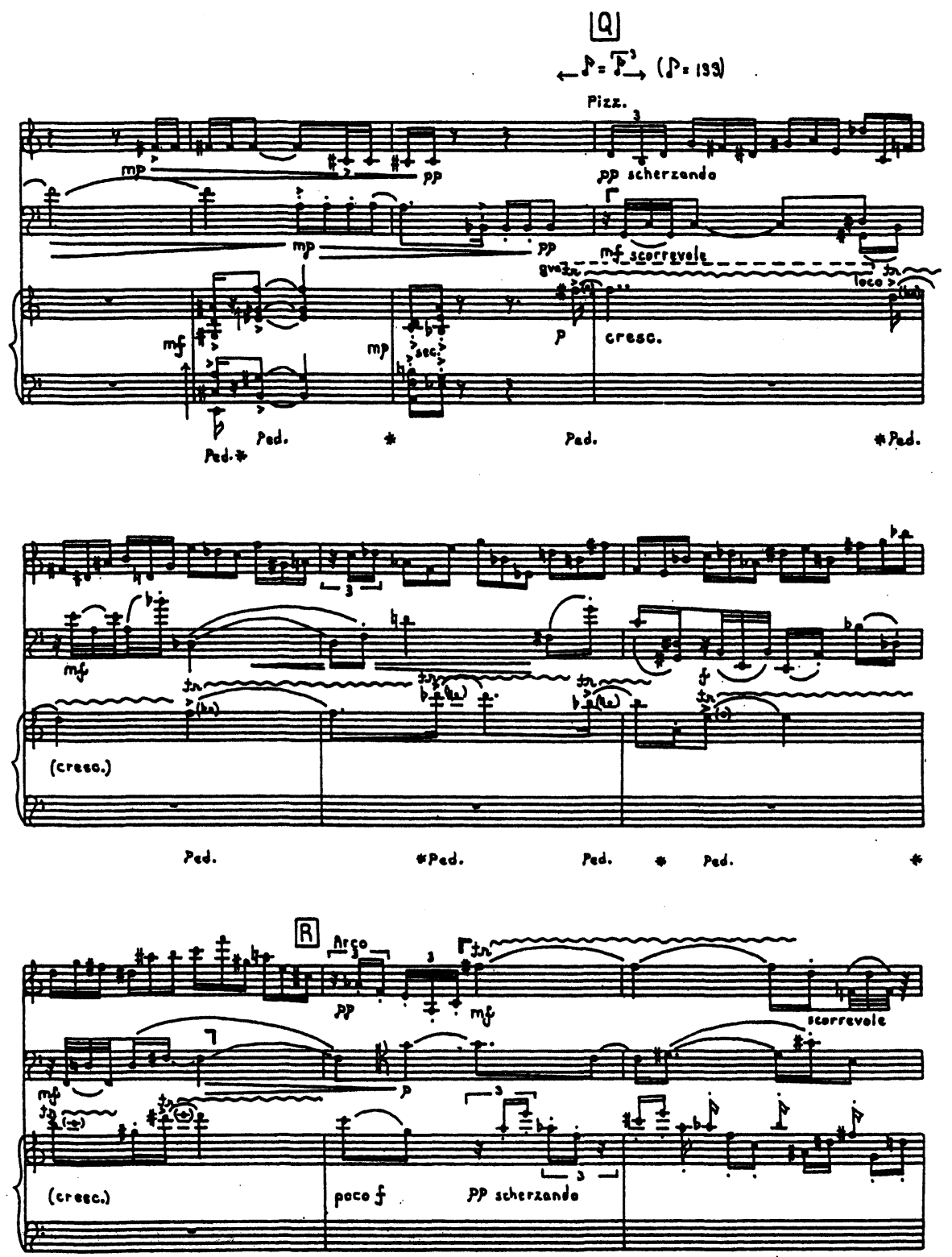

Ped. Ped. 

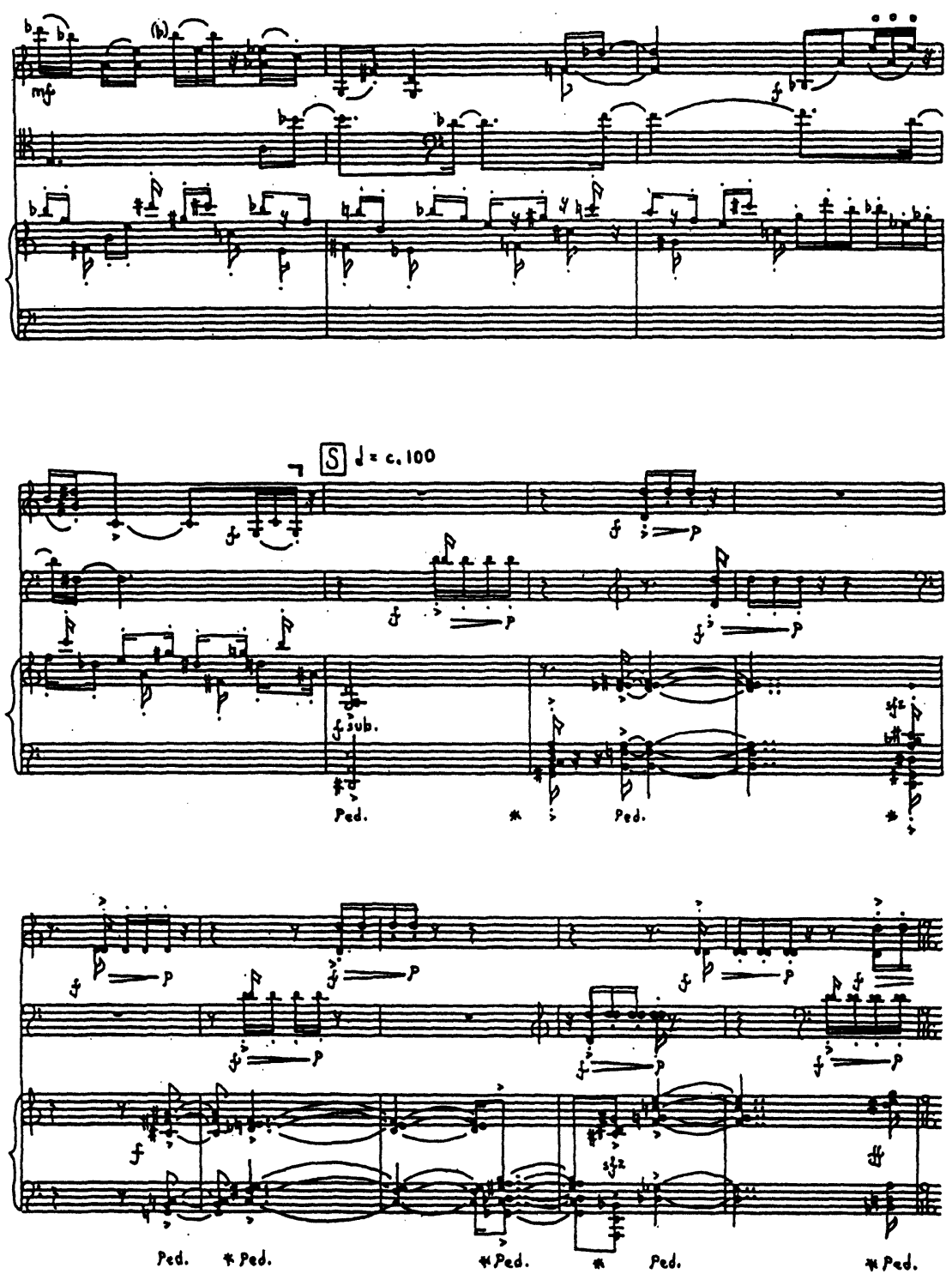


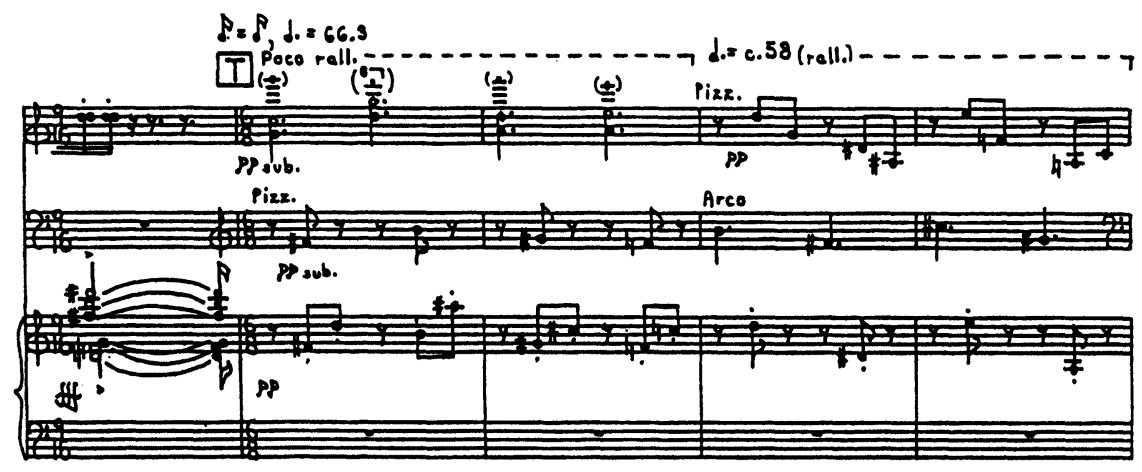

Ped.
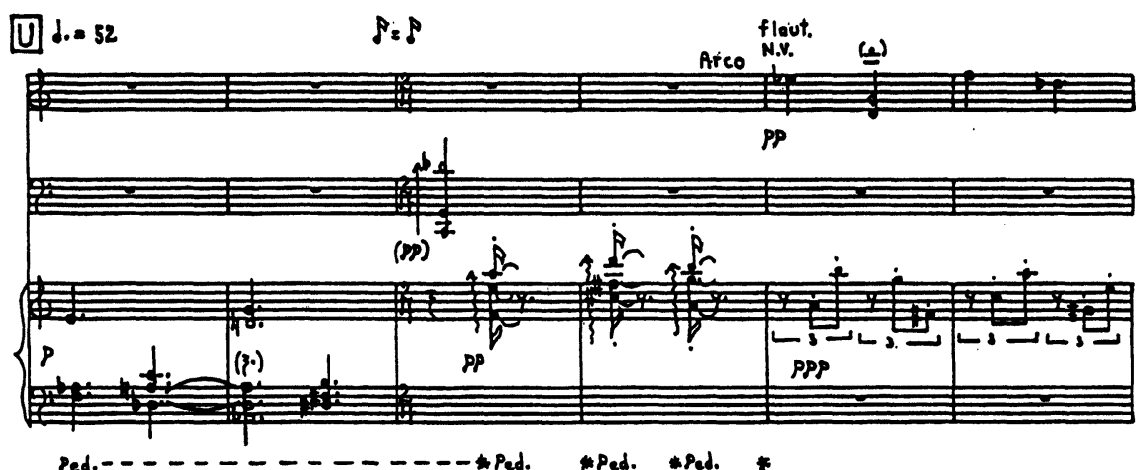

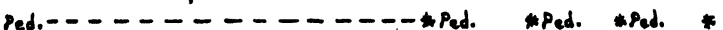

V] Accel...-.-

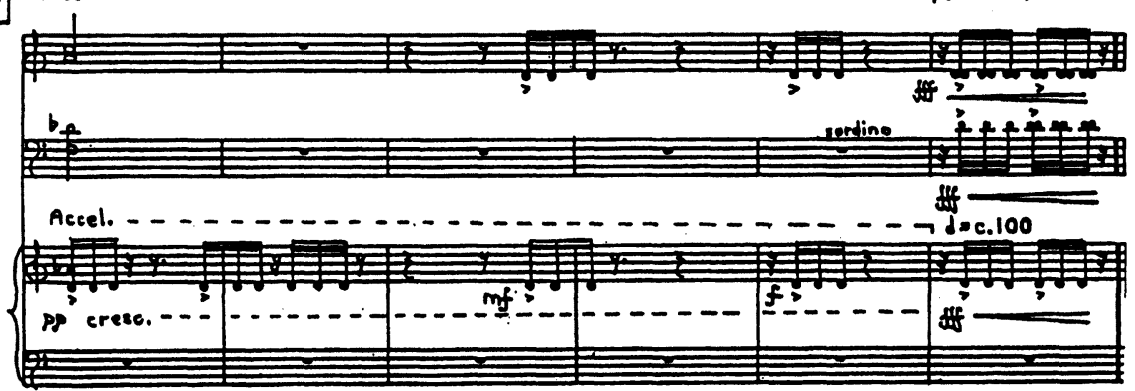

attacea 


\title{
REFERENCE LIST
}

Hasty, Christopher. 1997. Meter as Rhythm. New York: Oxford University Press. Horlacher, Gretchen G. 2001. "Bartók's 'Change of Time': Coming Unfixed." Music Theory Online 7, no. 1 (January).

Mamlok, Ursula. 1984a. Nahua Songs. Aleck Karis, pianoforte, Benjamin Hudson, violin, and Chris Finckel, cello. CRI SD 518. Re-released on Mamlok (2002).

1984b. New Music Festival 4. Diana Smith, pianoforte; Paul Makara, violin; and Alan Smith, cello, Access S-101.

- 1999. The Music of Ursula Mamlok: Constellations, Der Andreas Garten, Girasol, Polarities, and String Quartet No. 2. Various performers. CRI CD 806.

- 2000. Contemporary American Piano Trios, vol. 2. The Francesco Trio. Music and Arts CD 933.

-2002. CRI American Masters: Ursula Mamlok (Panta Rhei, Variations for Solo Flute, When Summer Sang, Stray Birds, and Sextet). Various performers. CRI CD 891.

Prevost, Roxane. 2003. "A Woman Composer Among Men: A Theoretical Study of Ursula Mamlok's Serial Works." PhD diss., State University of New York at Buffalo.

Sadie, Stanley, ed. 2001. The New Grove Dictionary of Music and Musicians. Executive dir. John Tyrell. New York: Grove.

Slonimsky, Nicolas, and Laura Diane Kuhn. 2001. Baker's Biographical Dictionary of Musicians. New York: Schirmer Books.

\begin{abstract}
Although composer Ursula Mamlok (b. 1928) has gained prominence in the areas of performance, recording, and publishing, her music has been largely neglected by scholars. This paper focuses on the fourth movement of her popular trio Panta Rhei (1981), specifically on the return of a distinctive repeated-note unit at the beginning and throughout the refrains. Mamlok varies the entries of the repeated-note unit so that perceived accelerations and decelerations, as described by Christopher Hasty, occur. By completing projections early or late, Mamlok's work gives the impression of "time in flux" or Panta Rhei.
\end{abstract}

\section{Résumé}

La musique d'Ursula Mamlok (1928-) n'a pas attiré l'attention des chercheurs, même si la compositrice est devenue une figure marquante sur le triple plan de l'interprétation, de l'enregistrement et de l'édition. Le présent article s'attarde sur le quatrième mouvement de son trio bien connu, Panta Rhei (1981), en particulier sur la répétition d'un motif frappant de note répétée au début et pendant les refrains. Mamlok varie les entrées du motif, de sorte que surviennent des accélérations et décélérations, comme l'a décrit Hasty. En complétant tôt ou tard les projections, l'œuvre de Mamlok donne l'impression d'un « temps continu » ou Panta Rhei. 